\title{
RECENT RESULTS ON CLEANING AND CONDITIONING THE ATF VACUUM SYSTEM*
}

\author{
R. A. Langley, T. L. Ciark, J. C. Glowienka, R. H. Goulding, \\ P. K. Mioduszewski, D. A. Rasmussen, T. F. Rayburn, \\ C. R. Schaich, T. D. Shepard, J. E. Simpkins, J. L. Yarber
}

DE89 012971

Oak Ridge National Laboratory, Oak Ridge. TN 37831-8072

\begin{abstract}
Techniques for cleaning and conditioning the vacuum vessel of the Advanced Toroidal Facility (ATF) and its intemal components are described. The vacuum vessel cleaning technique combines baking to $150^{\circ} \mathrm{C}$ and glow discharges with hydrogen gas. Chromium gettering is used to further condition the system. The major internal components are the anodized aluminum baffles in the Thomson scattering system, a graphite-shielded ICRF antenna, two graphite limiters, and a diagnostic graphite plate. Three independent heating systems are used to bake some of the major components of the system. The major characteristics used for assessing cleanliness and conditioning progress are the maximum pressure attained during bakeout, the results of gas analysis, and relevant plasma parameters (e.g., time to radiative decay). Details of the various cleaning and conditioning procedures and results are presented.
\end{abstract}

\section{INTRODUCTION}

The ATF is an $\mathcal{C}=2,12$-field-period torsatron, a member of the stellarator family of fusion confinement systems. ${ }^{1}$ It has a major radius $R_{0}=2.1 \mathrm{~m}$ and an average minor radius $a=0.3 \mathrm{~m}$ and has operated with a maximum magnetic field of $1 \mathrm{~T}$. The facility has operated with a maximum of $0.2 \mathrm{MW}$ of electron cyclotron heating for currentless target plasma production and with up to $2 \mathrm{MW}$ of neutral beam injection for bulk plasma heating. Experimental research on the ATF is directed toward auvancing toroidal confinment physics in a number of areas, including beta limits, transport, heating, particle and energy control, and impurity behavior. To ensure an acceptable base vacuum and "clean" walls, cleaning and conditioning of the vacuim vessel and some of the major internal components were incorporated into the initial design.

In Sec. II, the properties of the vacumm vessel and pumping system are summarized. The vessel bakeout system and the glow discharge cleaning (GDC) procedure are described in Sec. III. In Sec. IV, we describe procedures for cleaning and

*Rescarch sponsored by the Orfice of Fusion Energy, L.S. Department of Energy, under contrac: DE-AC05-84OR21100 with Martin Marietta Energy Systems, Inc. 
conditioning some of the internal components and discuss the results obtained. Chromium gettering is addressed in Sec. V. In Sec. VI, we discuss the effects of the various cleaning and conditioning techniques on plasma performance. Finally, in Sec. VII we summarize and draw conclusions from the present results.

\section{VACUUM VESSEL AND PUMPING SYSTEM}

The ATF vacuum vessel is fabricated from nonmagnetic stainless steel plates welded with Inconel filler metal. Heating sources, pumping system components, and diagnostics are coupled to the device through 48 ports of 3 different sizes. Figure 1 shows the vacuum vessel configuration. The complicated shape is designed to accommodate the two helical torsatron windings shown in Fig. 2.

The vacuum vessel consists of the basic torus, including the port throats, and the flanges, each of which is made up of a flange window attached to the port throat and a flange cover (see Fig. 1). Figure 3 is a schematic of the vacuum vessel, the pumping system, and the major internal components. Pertinent surface areas are listed in Table I. The high-vacuum pumping system for the vacuum vessel consists of three $2200-\mathrm{L} / \mathrm{s}$ turbopumps in parallel, each backed with a forepump. The effective speed of the pumping station at the vessel was calculated to be $3200 \mathrm{~L} / \mathrm{s}$, and the measured pumping speed was $2500 \mathrm{~L} / \mathrm{s}$. Two residual gas analyzers (RGAs) are installed in the pumping syste:n for gas analysis. A variable-conductance bypass arm is used for gas analysis during GDC.

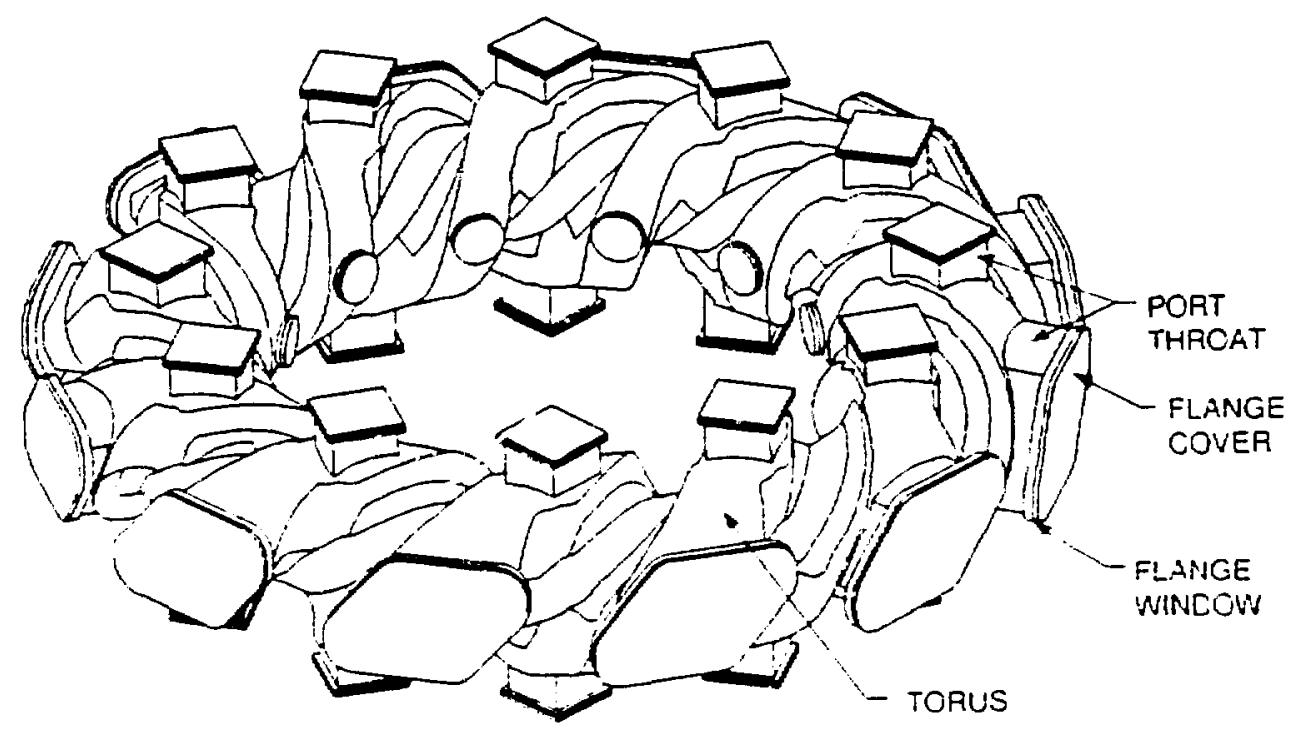

FIG. 1. Geometric configuration of the ATF vacuum vessel. 


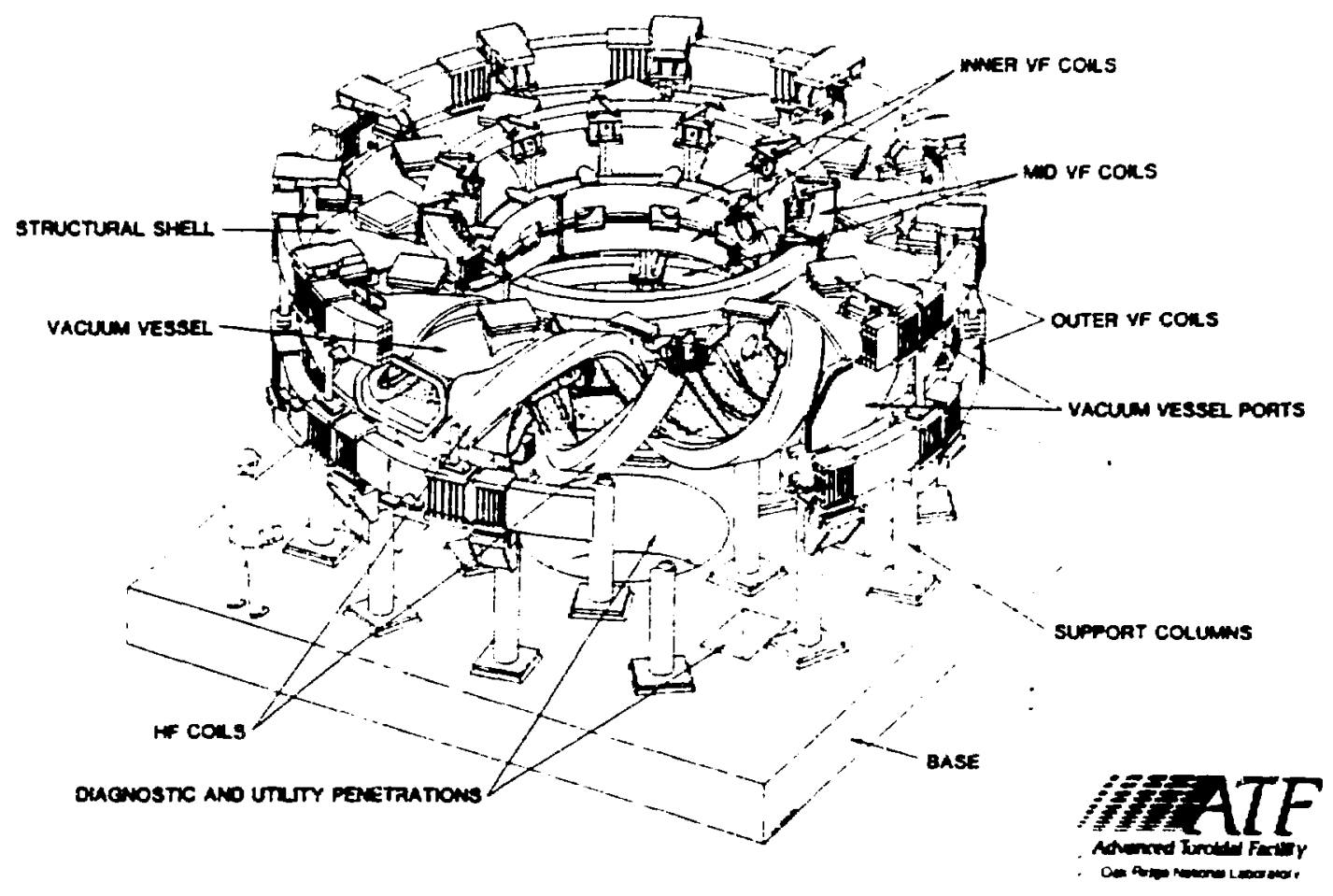

FIG. 2. Schematic of ATF device.

\section{BAKING AND GDC SYSTEMS}

Induction heating of the torus is accomplished by inductive coupling of ac power via excitation of the helical windings. About $20 \mathrm{~min}$ is needed to heat the torus to its maximum allowable temperature, $150^{\circ} \mathrm{C}$ at the hottest point in the vessel. The maximum heating rate is about $4^{\circ} \mathrm{C} / \mathrm{min}$, and the cooling rate near $150^{\circ} \mathrm{C}$ is abour $3^{\circ} \mathrm{C} / \mathrm{min}$. (Earlier estimates ${ }^{2}$ were $42 \mathrm{~min}$ to heat the torus to $150^{\circ} \mathrm{C}$, a heating rate of $3^{\circ} \mathrm{C} / \mathrm{min}$, and a cooling rate near $150^{\circ} \mathrm{C}$ of about $1^{\circ} \mathrm{C} / \mathrm{min}$.) When the maximum temperature is reached, the power is turned off and the temperature is allowed to drop to $140^{\circ} \mathrm{C}$ before power is reapplied. The cycle time for the induction heating is about $6 \mathrm{~min}$, with $2.5 \mathrm{~min}$ on and $3.5 \mathrm{~min}$ off. The inductive coupling of the helical coils to the vessel is somewhat nonuniform; when the hottest portion of the vessel is at $150^{\circ} \mathrm{C}$, the coolest portion is near $75^{\circ} \mathrm{C}$.

Heating tapes are used to heat the torus appendages; each tape is independently' controlled using a thermocouple as a sensor. The time to react the maximum allowable temperature of all appendages heated with tapes, except the Thomson scattering stack, is very long (i.e., many hours). In fact, for a majority of the tapes, the 


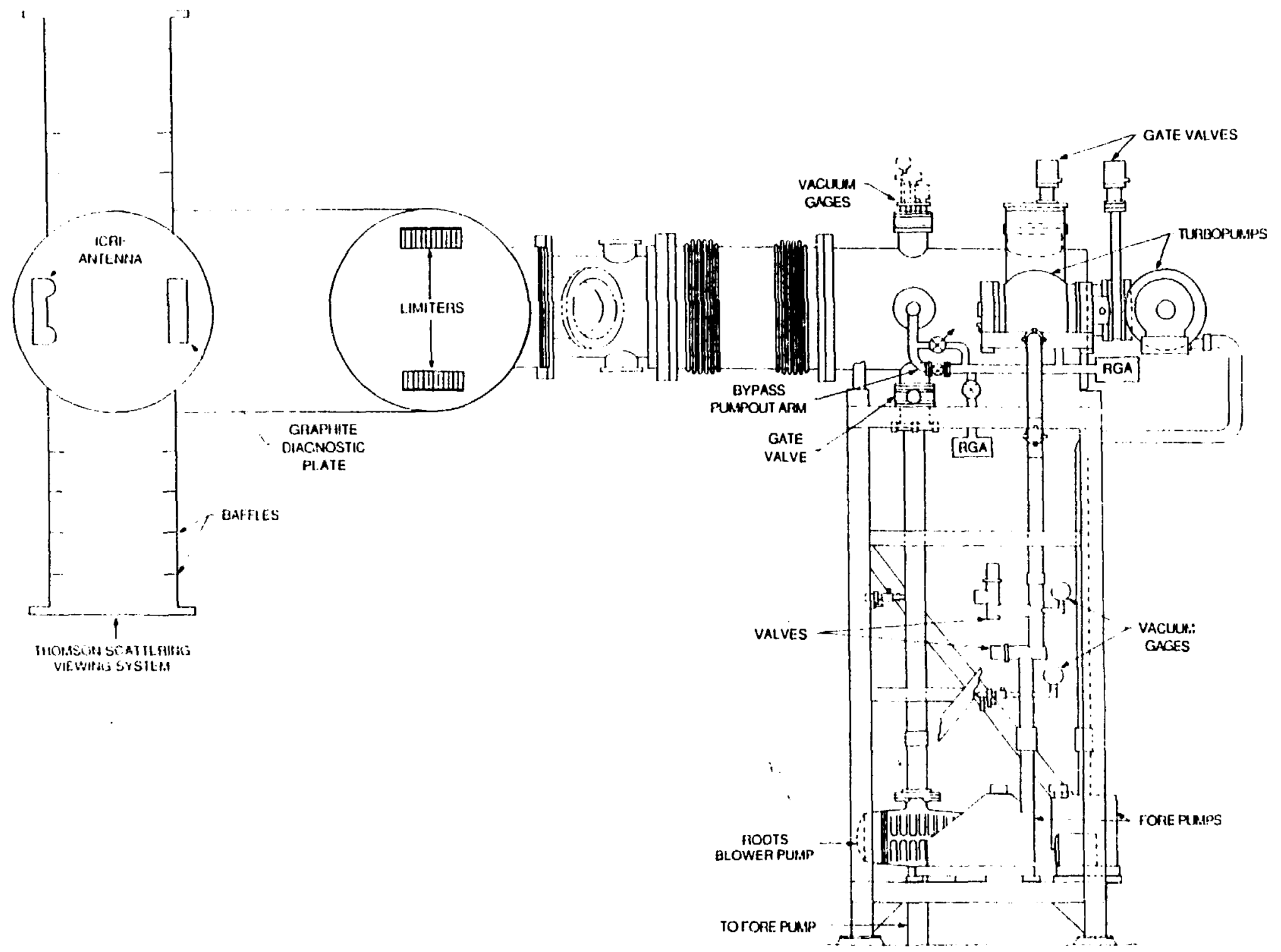

FIG, 3. Schematic of ATF vacuum vessel, najor internal components, and pumping system. 


\begin{tabular}{lccc} 
& $\begin{array}{c}\text { Plasma facing area } \\
\left(\mathrm{m}^{2}\right)\end{array}$ & SRF & $\begin{array}{c}\text { Outgassing area } \\
\left(1000 \times \mathrm{m}^{2}\right)\end{array}$ \\
\hline $\begin{array}{l}\text { Vacuum vessel } \\
\text { Stainless steel }\end{array}$ & 50 & 10 & 0.5 \\
$\begin{array}{l}\text { Thomson scattering stack } \\
\text { Anodized aluminum } \\
\text { Stainless steel }\end{array}$ & 0 & 100 & 3 \\
$\begin{array}{l}\text { Limiters } \\
\text { AXF-5Q }\end{array}$ & 0 & 10 & 0.1 \\
$\begin{array}{l}\text { Graphite diagnostic plate } \\
\text { ATJ }\end{array}$ & 0.2 & & 10 \\
$\begin{array}{l}\text { ICRF antenna shield } \\
\text { AXF-5Q }\end{array}$ & 0.06 & & 15 \\
\hline
\end{tabular}

equilibrium temperature is less than $150^{\circ} \mathrm{C}$, so these tapes remain on continuously during the heating cycle.

GDC with hydrogen is used extensively in conjunction with baking. Salient features of this widely used technique are described in a recent review by Dylla. ${ }^{3}$ For ATF, initial breakdown occurs at about $15 \mathrm{mTorr}$ for a "dirty" vessel and about 40 mTorr for a relatively "clean" vessel at applied voltages near $1 \mathrm{kV}$. The power supply is limited to $1 \mathrm{kV}$ and $2.5 \mathrm{~A}$. For the geometry of our system, the hydrogen flux to the wall is about $2 \times 10^{13} \mathrm{H}_{2}^{+} / \mathrm{cm}^{2} \cdot \mathrm{s}$ at $600 \mathrm{~V}, 2 \mathrm{~A}$, and an operating pressure of 2 $m$ Torr. This pressure was chosen because it was the lowest pressure at which a glow discharge could be reliably maintained while still pumping without significant damage to the turbopumps.

We have found an efficient method of operation that permits simultaneous baking and GDC. The magnetic field created when the helical coils are used for induction heating significantly reduces the size of the glow volume, so little effective cleaning takes place during the heating phase, but cleaning does occur during the cooling phase. This provides GDC about $58 \%$ of the time. 


\section{CLEANING AND CONDITIONING OF THE INTERNAL COMPONENTS}

The pertinent surface areas of the vessel and major intemal components are given in Table 1. The plasma-facing areas and the outgassing areas are based on reasonable estimates for the surface roughness factor and the measured area per unit mass for the graphite components.

\section{A. Thomson scattering stack}

It was thought to be necessary to begin the cleaning process by cleaning the black anodized aluminum apertures in the Thomson scaitering stack, since they are somewhat removed from the plasma region. The anodization layer is about $40 \mu \mathrm{m}$ thick. In addition, it was felt that the remaining parts of the system should be kept hot during this cleaning so that the smallest possible amount of the outgassing constituents would be adsorbed. GDC was not performed during this operation, since the outgassing gases would have been implanted into the surface region of the vessel walls. The maximum pressure reached during a baking operation, starting with the initial cleaning and conditioning operation after a major opening, is shown in Fig. 4. The estimated amount of gas released (mainly water, as determined by RGA) is given in Table II. Figure 5 shows pressure versus time for the second bake cycle. The time for a bake cycle is about $5 \times 10^{4} \mathrm{~s}$ at a temperature of about $150^{\circ} \mathrm{C}$. The power for

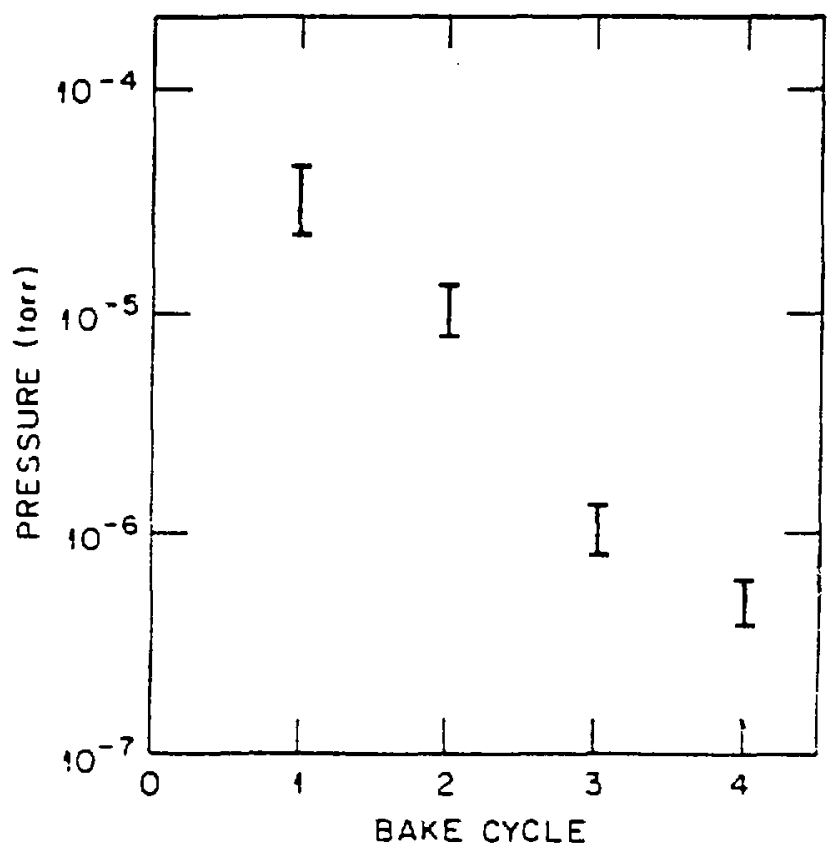

FIG. 4. Maximum pressure reached during baking cycle for ATF. 
Table II. Estimated $\mathrm{H}_{2} \mathrm{O}$ released from Thomson scattering stack

(Bake duration: $5 \times 10^{4} \mathrm{~s}$, bake temperature: $150^{\circ} \mathrm{C}$ )

\begin{tabular}{lr}
\hline $\begin{array}{l}\text { Baking } \\
\text { cycle }\end{array}$ & $\begin{array}{c}\text { Gas released } \\
\text { (Torr.L) }\end{array}$ \\
\hline 1 & 1000 \\
2 & 300 \\
3 & 50 \\
4 & 1 \\
\hline
\end{tabular}

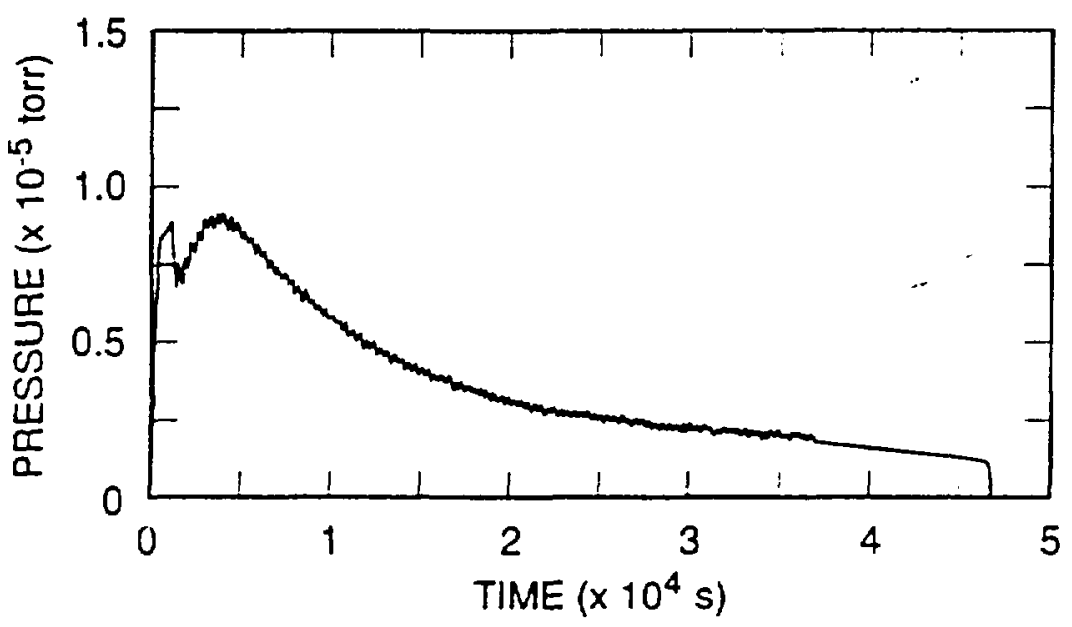

FIG. 5. Pressure response during second baking cycle of Fig. 4.

induction heating and for all heating tapes was stared at approximately the same time. The initial rise can be attributed to induction heating of the vessel; the second peak, to gas released from the anodized aluminum. The jagged nature of the pressure response results from the on-off cycling of the induction heating system. After five baking cycles, no detectable release of any gas occurred when the Thomson scattering stack was baked further. This simple procedure appeared to clean this component sufficiently for plasma operation. Note that this component has essentially no plasmafacing surface, so no conclusions can be drawn as to its capability as a plasma-facing surface.

\section{B. ICRF antenna}

The ICRF antenna is a resonant double loop antenna oriented for fast-wave launch. It operates in the range from 10 to $30 \mathrm{MHz}$ and will launch up to $800 \mathrm{~kW}$ in 
plasma for poriods of $\leq 500 \mathrm{~ms}$. It has a two-tier, graphite-shielded Faraday shield and graphite armor tiles on its sides. It is movable radially over a $15-\mathrm{cm}$ range. The launching area is $21 \times 36 \mathrm{~cm}$, and the outside dimensions are $27 \times 42 \mathrm{~cm}$. The pertinent areas are given in Table $I$. The antenna was initially conditioned during the bake and GDC procedure described above and further conditioned (both for launching RF power and for preventing vacuum contamination) through operation at increasing power levels, ultimately to $100 \mathrm{~kW}$ in vacuum. The residual gas spectrum was monitored during this process. Significant outgassing was observed only when the antenna operated in the multipactor breakdown regime, 4 i.e., the $7-$ to $8-\mathrm{kW}$ power range. Figure 6 shows partial pressure vs time during operation in this regime with 100-ms pulses applied every $10 \mathrm{~s}$. The dominant mass peaks released, 28, 44, and 15 , represent $\mathrm{CO}, \mathrm{CO}_{2}$, and $\mathrm{CH}_{4}$. The amount of each gas released is given in Table III. Operation in this regime did not appear to clean or condition the antenna for plasma operation. However, the initial vacuum conditioning accomplished with the bake and

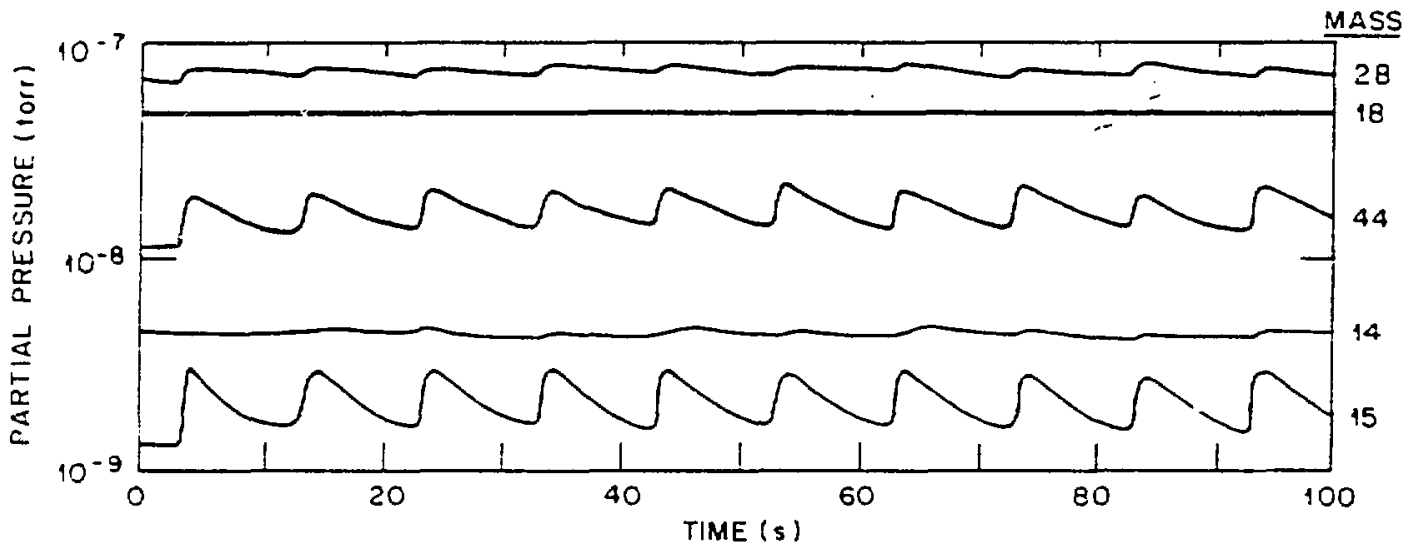

FIG. 6. Partial pressure of five dominant mass peaks vs time during voltage conditioning of ICRF antenna, taken during multipactor breakdown regime (see text).

Table III. ICRF antenna conditioning (operating in multipactor breakdown regime, $7-8 \mathrm{~kW}$ and 100 -ms pulses)

\begin{tabular}{cl}
\hline $\begin{array}{c}\text { Major species } \\
\text { released }\end{array}$ & $\begin{array}{l}\text { Amount per } \\
\text { pulse (Torr.L) }\end{array}$ \\
\hline $\mathrm{CO}$ & $1.5 \times 10^{-4}$ \\
$\mathrm{CO}_{2}$ & $1 \times 10^{-4}$ \\
$\mathrm{CH}_{4}$ & $2.5 \times 10^{-5}$
\end{tabular}


GDC procedure allowed very fast conditioning for launching RF power; only a few hours of conditioning were needed, in contrast to previous experience with other antennas that required many days of conditioning.

\section{Limiters and diagnostic plate}

The limiters, which are made of AXF-5Q graphite, are located at the top and the bottom of the torus (see Fig. 3). They are segmented, instrumented, and movable. They were cleaned and baked before being inserted into the torus but were exposed to air for several weeks after insertion and before pumpdown. The area per unit mass of this type of graphite, as determined by the BET technique, ${ }^{5}$ is about $1 \mathrm{~m}^{2} / \mathrm{g}$. The diagnostic plate is similar to the limiters in many respects but is made of ATJ graphite. Like the limiters, it was cleaned and baked before insertion in the torus, but it was exposed to air for a few days before pumpdown. No independent method was designed for in situ baking of either the limiters or the diagnostic plate, so these components provide large possible outgassing sources when they are heated and interact with atomic hydrogen.

\section{GETTERING}

Two chromium getter sources that have been installed in ATF provide surface coverage of about $30 \%$ of the vessel area. In a typical getter cycle, each source is heated to $1150^{\circ} \mathrm{C}$ and yields a sublimation rate of $0.1 \mathrm{~g} / \mathrm{h}\left(10^{16} \mathrm{atoms} / \mathrm{cm}^{2} \cdot \mathrm{s}\right)$. The deposition process is continued for $30 \mathrm{~min}$ and deposits an average of 5 monolayers of chromium. The results following the small number of getter cycles that have been completed are much better than those obtained when only the bake and GDC procedure was used.

\section{PLASMA PERFORMANCE}

Wall cleanliness influences many plasma properties; those most prominently affected are density, stored energy, and radiative losses. Initial plasma operation after a major opening is characterized by breakdown with no external gas applied and by a large influx of impurities from the wall, due to particle-induced desorption. This leads to radiative collapse terminating the plasma. An unforiunate incident that occurred after a relatively long baking and GDC cycle made it possible to compare the efficacy of the different cleaning and conditioning techniques. A bake ard GDC sequence was inadvertently initiated with air instead of hydrogen; this led to a rather "dirty" wall and very poor plasma performance. A sequence of baking and GDC with hydrogen was then carried out; plasma performance following this sequence was significantly better. This was followed by a gettering cycle and plasma operation, during which plasma performance again improved significantly. In Fig. 7, time from the start of 


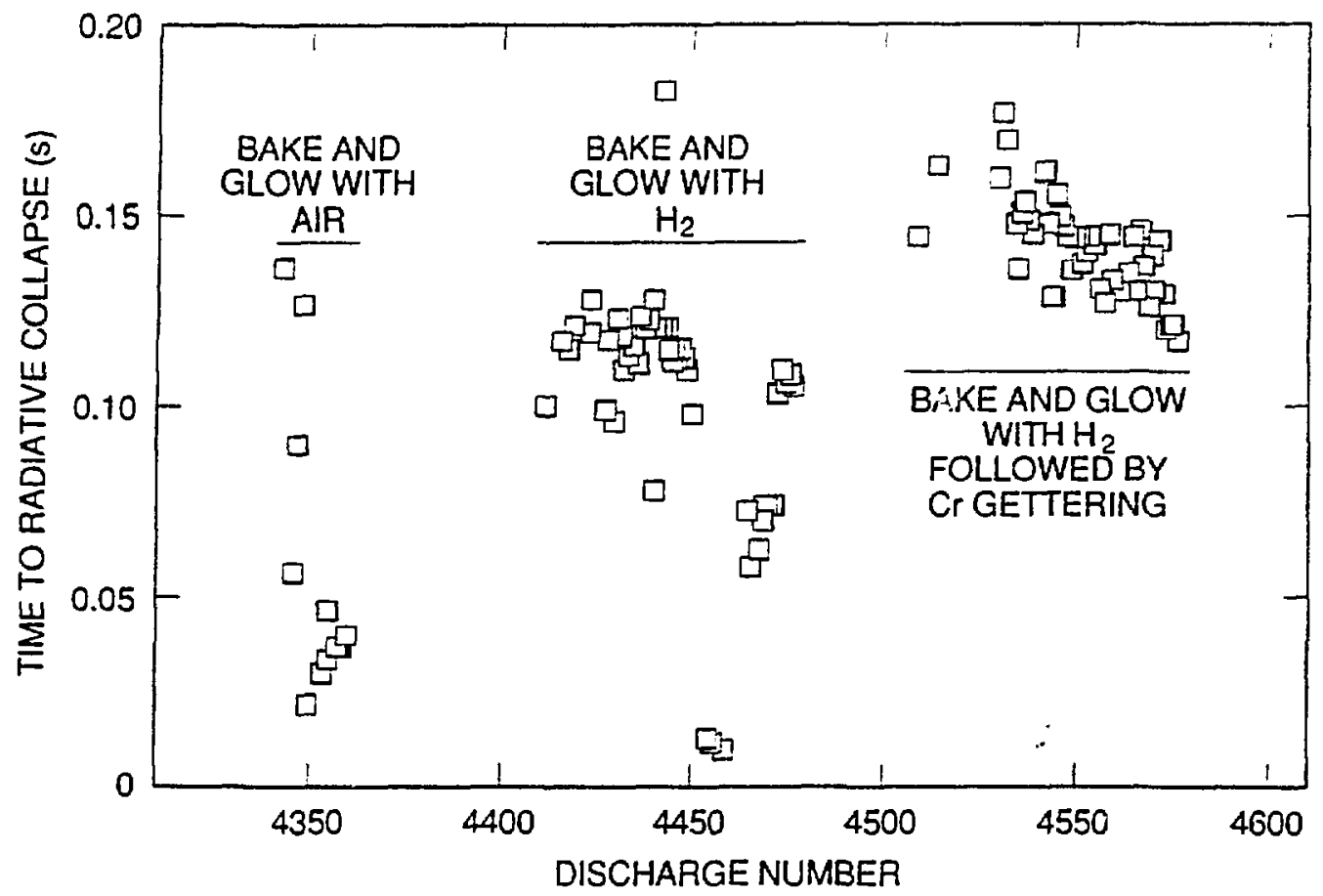

FIG. 7. Time from beginning of neutral beam injection to radiative collapse. Data are from discharges during the operating periods following three conditioning sequences.

neutral beam injection to radiative collapse is shown as a function of discharge number for shots taken during the operating periods following these three "conditioning" sequences. Figure 8 shows the peak stored energy for the same discharges. The plasma parameters improve significantly as the walls are cleaned and conditioned.

\section{SUMMARY}

The procedures used for cleaning and conditioning of ATF have been described. Two significant results were obtained. First, baking to $150^{\circ} \mathrm{C}$ can clean anodized aluminum sufficiently for operation in a plasma device, but not necessarily as a plasma-facing component. Second, the cleaning and conditioning procedure described here can clean a graphite-protected ICRF antenna sufficiently to allow rather rapid conditioning for launching $R F$ power. 


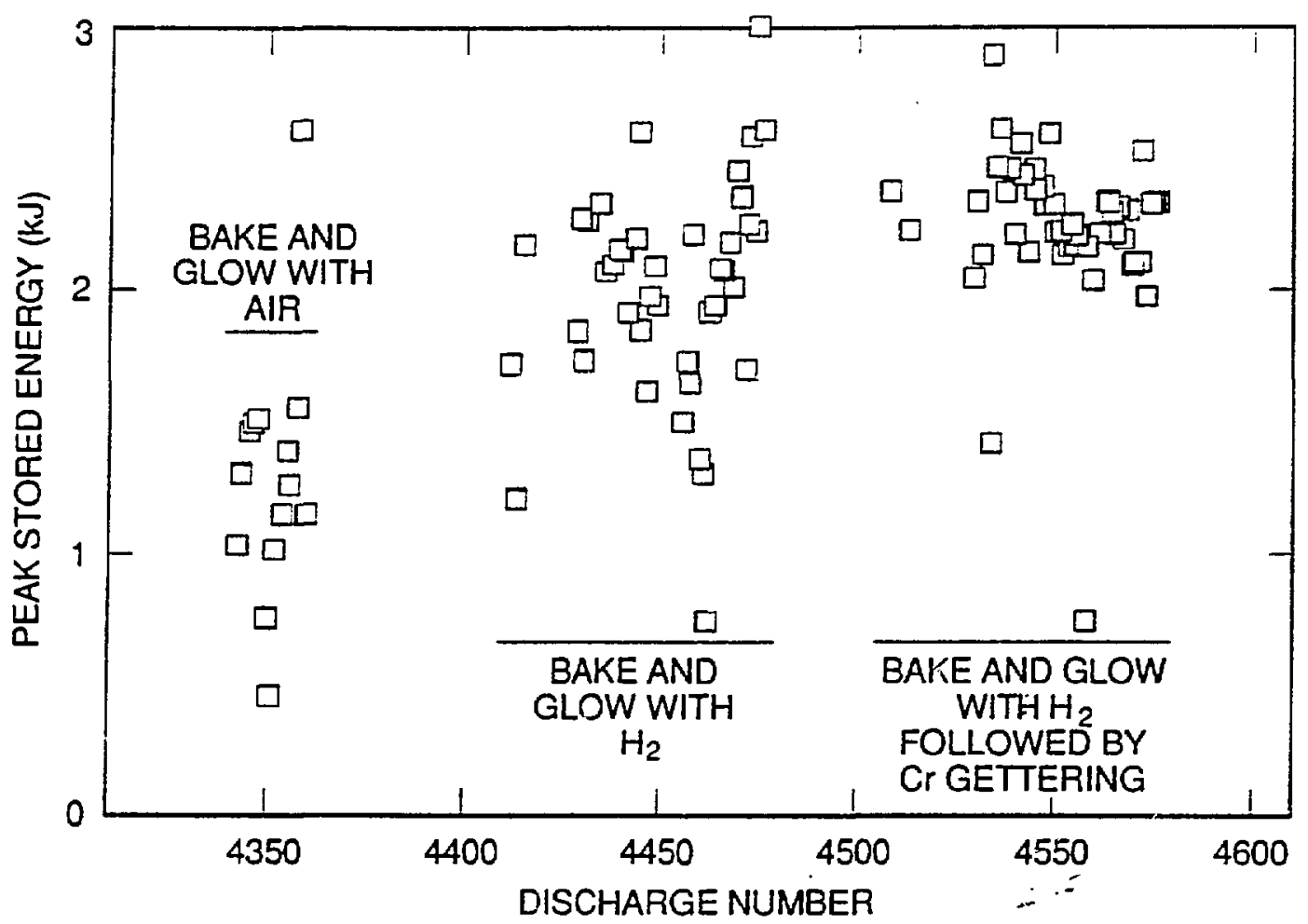

FIG. 8. Peak stored energy in the plasma. Data are from discharges during the operating periods following three conditioning sequences.

\section{ACKNOWLEDGMENTS}

The authors thank the entire ATF team for its cooperation and help.

\section{REFERENCES}

1. J. F. Lyon et al., Fusion Technol. 10, 179 (1986).

2. R. A. Langley et al., J. Vac. Sci. Technol. A6 (1988) 1288.

3. H. F. Dylla, J. Vac. Sci. Technol. A6 (1988) 1276.

4. J. Arbez et al., Fusion Technol. 1 (1984) 669.

5. R. A. Causey, M. I. Baskes, and K. L.Wilson, J. Vac. Sci. Technol. A4 (1986) 1189.

\section{DISCLAIMER}

This report was prepared as an account of work sponsored by an agency of the United Stales Government. Neither the United States Government nor any agency thereof, nor any of their employees, makes any warranty, express or implied, or assumes any legal liability or responsibility for the accuracy, completeness, or usefulness of any information, apparatus, iproduct, or process disclosed, or represents that its use would not infringe privately owned rights. Reference herein to any specific commercial product, process, or service by trade name, trademark. manufacturer, or otherwise does not necessarily constitute or imply its endorsement, recommendation, or favoring by the United States Government or any agency thereof. The views and opinions of authors expressed herein do not necessarily state or reflect those of the United States Government or any agency thereof. 